\title{
Health management effect of different intervention strategies on cardiovascular disease and its risk factors.
}

\author{
Lijun Guo' ${ }^{1}$, Yong Bao ${ }^{2,3 *}$ \\ ${ }^{1}$ College of Health Information Technology and Management, Shanghai University of Medicine and Health Sciences, \\ Shanghai, PR China \\ ${ }^{2}$ Shanghai Jiao Tong University School of Public health, Shanghai, PR China \\ ${ }^{3}$ Hongqiao International Institute of Medicine, Shanghai Jiao Tong University School of Medicine, Shanghai, PR China
}

\begin{abstract}
With the arrival of advancements in modern medicine, most of the aging related diseases have attained great attention in the era. The disease of the elderly may affect their related activities, and even cause serious threat to the life. Demographic transitions have occurred in the field of geriatrics in China. The senile diseases have also showed a rising trend. In this paper, health effects and different intervention strategies on cardiovascular disease and its risk factors were analysed. The results show that taking the necessary intervention strategies can further ensure the prevention of cardiovascular disease in the elderly population.
\end{abstract}

Keywords: Intervention strategy, Cardiovascular disease, Risk factors, Senile diseases.

Accepted on May 22, 2017

\section{Introduction}

Under the trend of the times and the background, the development of the aging society has brought some negative effects on the development of the times and the world. With the increasing number of elderly people, the outbreaks of senile diseases have a great impact on the normal life and mental state of the elderly. This will adversely affect the safety of life in the elderly in the absence of timely prevention and intervention.

At present, cardiovascular disease has become one of the main diseases that harm the elderly. Cardiovascular diseases are one of the major health hazard that may have a negative impact on the normal life and activities of the elderly. Therefore, it is necessary to implement different intervention strategies for the management and prevention of cardiovascular diseases. The understanding and prediction of the main risk factors can provide a scientific basis for the improvement of the overall health level of the elderly [1].

\section{State of the Art}

\section{Research status of the effect of cardiovascular disease on the health of the elderly and its hazards}

Cardiovascular disease has gradually become one of the most important diseases affecting the health of the elderly, its impact on the health status of the elderly and its major hazards have been further studied. Many researchers believe that cardiovascular disease is mainly due to a certain degree of aging in the heart of the elderly, and the function of the heart is unable to maintain a normal blood transmission capacity, so as to cause some damage to the health of the elderly. Some researchers believe that cardiovascular disease is not only due to genetic role in the body, may also be due to climate reasons, as well as the body's own life habits and other factors [2]. In addition, cardiovascular disease may further lead to other related complications, so as to lead to a further decline in physical health and immunity of patients, and indirectly affect the patient's life safety. Therefore, it is necessary for the prevention and treatment of the relevant theories [3].

\section{The importance of intervention strategies for cardiovascular disease prevention and recovery}

Cardiovascular disease is very harmful to the human body, only the implementation of different intervention strategies can further promote the prevention and recovery of the disease. At present, there have been preoperative and postoperative intervention strategies mentioned. The mention of these interventions has a greater effect on the recovery of the relevant physical fitness in patients with cardiovascular disease [4,5], and many researchers believe that some appropriate intervention strategies and theories need to be put forward for the prevention of these diseases, only the better application of these strategies can provide more theoretical basis for the health of the elderly [6-8]. 


\section{Methodology}

\section{Current situation of cardiovascular disease incidence in China}

Along with our country entering the aging society step by step, cardiovascular disease has shown a gradual upward trend because of the unhealthy living habits. According to relevant reports, the prevalence of cardiovascular disease in China has increased year by year (Figure 1). Although the medical facilities and methods have been improved to some extent; the mortality is still high due to the characteristics of the disease, which seriously affects the lives and health of our people [9] Therefore, this study analyses the effects of different intervention strategies on cardiovascular disease prevention; the purpose is to provide some theoretical basis and scientific support for the people's health level.

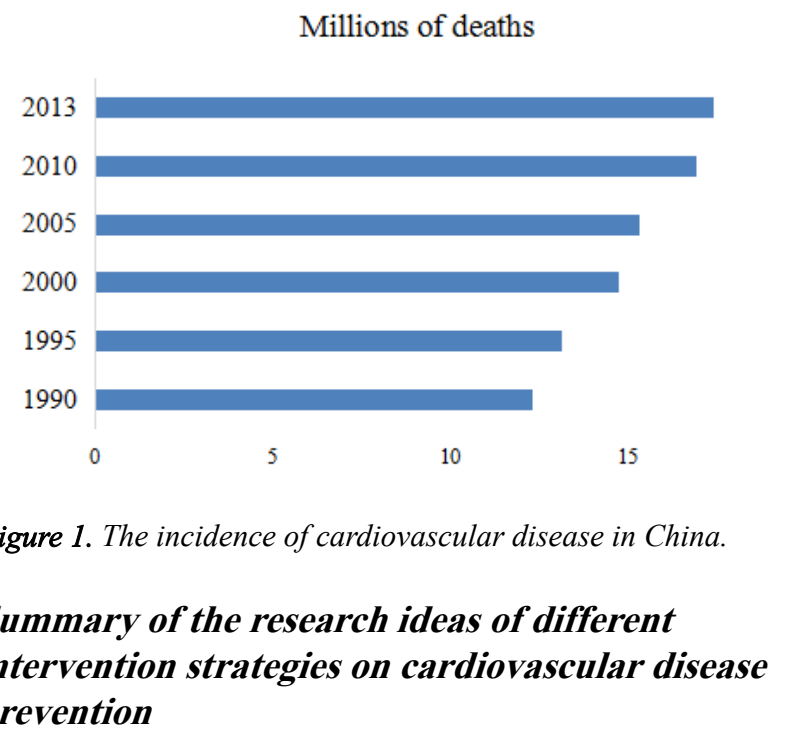

Firstly, this study inquired into the relevant information to determine the main intervention strategies for the prevention of cardiovascular disease, and further analysed the effectiveness of these interventions (Table 1).

Table 1. Summary of survey population for this study.

\begin{tabular}{llll}
\hline Age & The number of people & $\begin{array}{l}\text { The ratio of male } \\
\text { and female }\end{array}$ & Percent (\%) \\
\hline $35-45$ & 20 & $1.3: 1$ & 20.00 \\
\hline $45-55$ & 30 & $1: 1$ & 30.00 \\
\hline $55-65$ & 50 & $0.9: 1$ & 50.00 \\
\hline
\end{tabular}

\section{Result Analysis and Discussion}

\section{Analysis of major intervention strategies for prevention of cardiovascular disease and its risk factors}

Through the search of the relevant data, this study summarized the main intervention strategies for prevention of cardiovascular disease and its risk factors into 5 strategies (Table 2).

Table 2. Major intervention strategies for cardiovascular disease and its risk factors.

\begin{tabular}{ll}
\hline Intervention strategies & Detailed description \\
\hline Two kinds of prevention strategies & Population strategy; high strategy \\
\hline Multi factor long-term intervention & $\begin{array}{l}\text { A long-term intervention in a variety of risk } \\
\text { factors can reduce mortality and } \\
\text { morbidity. }\end{array}$ \\
\hline $\begin{array}{l}\text { Public methods and health } \\
\text { education }\end{array}$ & $\begin{array}{l}\text { Strengthening the construction of medical } \\
\text { and health; reducing unhealthy living } \\
\text { habits }\end{array}$ \\
\hline Integrated control & $\begin{array}{l}\text { The prevention of cardiovascular disease } \\
\text { can achieve the prevention of a variety of } \\
\text { chronic diseases }\end{array}$ \\
\hline
\end{tabular}

\section{The health status of patients with cardiovascular disease before and after applying intervention strategy}

Through the investigation of the change of the health status of the patients with cardiovascular disease before and after the intervention strategy, as can be seen from Figure 2 that that patients with cardiovascular disease had a certain degree of improvement in their psychological status, activity ability and self-care ability, and the incidence of other complications was further reduced.

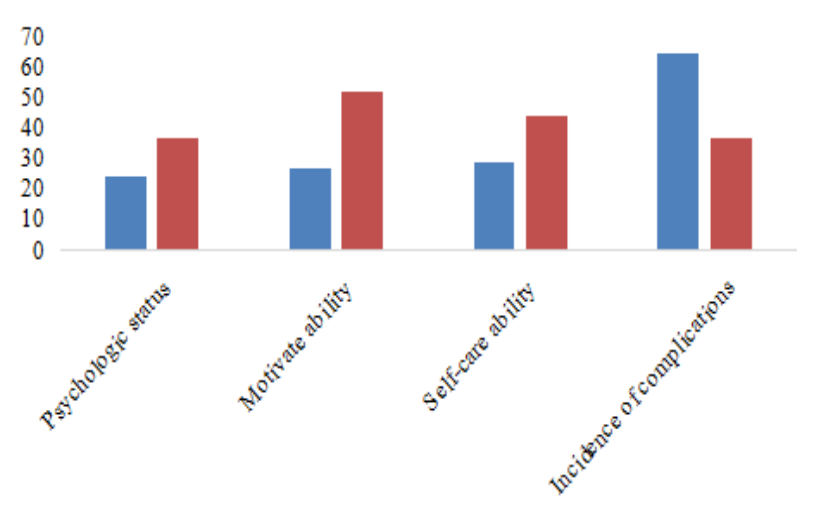

Before Over

Figure 2. Changes in health status of patients with cardiovascular disease before and after intervention strategies.

\section{Conclusions}

With the outbreak of cardiovascular disease, the intervention strategies for patients can effectively reduce the incidence and mortality of cardiovascular disease [10]. This study aimed at the current trend of increasing prevalence of cardiovascular disease in China, and summarized the different intervention strategies, and further analysed the changes of patients' life before and after the intervention strategies. The results show that the intervention strategies have a positive effect on the recovery of cardiovascular disease. 


\section{Acknowledgement}

National Natural Science Foundation of China (71373159); Ministry of Education (13YJAZH003); Shanghai Municipal Commission of Health and Family Planning (201640338, The fourth-round Three-year Public Health Action Plan (2016) No. 3); Hongqiao International Institute of Medicine, Shanghai Jiao Tong University School of Medicine ((2014) No.79); Science and Technology Department of Henan Province (162102310118); Seed Fund of Shanghai University of Medicine and Health Sciences ((2015) No.39).

\section{References}

1. Chen W, Gao RL, Liu LS, Zhu ML, Wang W, Wang YJ, Wu ZS. China cardiovascular diseases report 2015: a summary. J Geriatr Cardiol 2017; 14: 1-10.

2. Gupta RA, Shah N, Wang KC. Long non-coding RNA hot air reprograms chromatin state to promote cancer metastasis. Nature 2010; 464: 1071-1076.

3. Fernandez-Ruiz I. Immune system and cardiovascular disease. Nat Rev Cardiol 2016; 13: 503.

4. Ralph S, Claes H, Rebekkah B, Ola V, Emil H, Eva L, Paul A, Christopher BG, Judith H, Richard D. Physical activity in patients with stable coronary heart disease: an international perspective. Eur Heart J 2013; 34: 3286-3293.

5. Thompson PD, Buchner D, Piña IL, Balady GJ, Williams MA, Marcus BH, Berra K, Blair SN, Costa F, Franklin B, Fletcher GF. Exercise and physical activity in the prevention and treatment of atherosclerotic cardiovascular disease. Arterioscl Thromb Vasc Biol 2003; 23: 42-49.
6. Darden D, Richardson C, Jackson EA. Physical activity and exercise for secondary prevention among patients with cardiovascular disease. Curr Cardiovasc Risk Rep 2013; 7: 10.

7. Chu P, Pandya A, Salomon JA, Goldie SJ, Hunink MM. Comparative effectiveness of personalized lifestyle management strategies for cardiovascular disease risk reduction. J Am Heart Assoc 2016; 5: 002737.

8. Sacco RL, Roth GA, Reddy KS, Arnett DK, Bonita R, Gaziano TA, Heidenreich PA, Huffman MD, Mayosi BM, Mendis S, Murray CJ. The heart of 25 by 25: Achieving the goal of reducing global and regional premature deaths from cardiovascular diseases and stroke. Circulation 2016; 133: 674-690.

9. Pennathur A, Gibson MK, Jobe BA. Oesophageal carcinoma. Lancet 2013; 381: 400-412.

10. Jian-Bing W, Jin HF, Sanford MD, Rashmi S, Neal DF, Philip RT, You LQ, Christian CA. Dietary components and risk of total, cancer and cardiovascular disease mortality in the Linxian Nutrition Intervention Trials cohort in China. Sci Rep 2016; 6: 22619.

\section{*Correspondence to}

Yong Bao

Hongqiao International Institute of Medicine

Shanghai Jiao Tong University School of Medicine

PR China 